Implementation of the Balanced Scorecard as an effective performance measurement system in star-class hotels in Sri Lanka

By

H. M. S. R. Dayabandara

5266 FM 2012009

MBA 
Implementation of the Balanced Scorecard as an effective performance measurement system in star-class hotels in Sri Lanka

By

H. M. S. R. Dayabandara

5266 FM 2012009

A research submitted to the University of Sri Jayewardenepura in partial fulfillment of the requirements for the Degree of Master of Business Administration on Finance. 
The work described in this research was carried out by me under the supervision of Dr. Dileepa N. Samudrage and a report on this has not been submitted in whole or in part to any university or any other institution for another Degree/ Diploma.

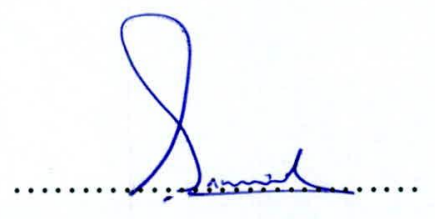

H. M. S. R. Dayabandara 
I certify that the above statement made by the candidate is true and that this research is suitable for submission to the University for the purpose of evaluation.

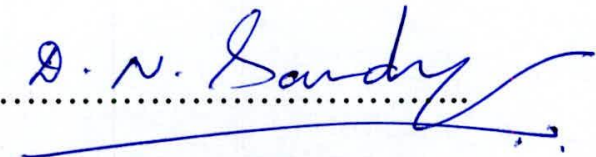

Dr. Dileepa N. Samudrage
Date: $31-05-2015$ 


\section{Table of Contents}

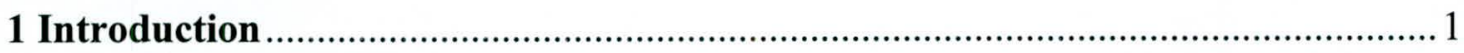

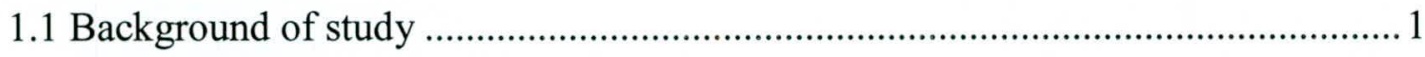

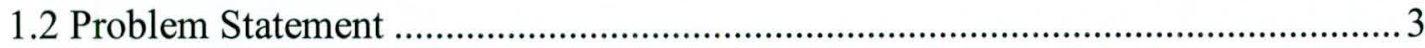

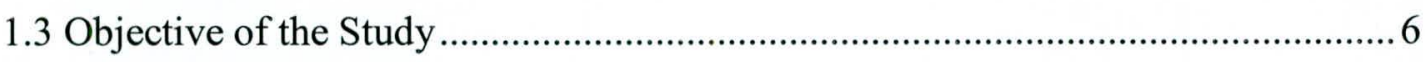

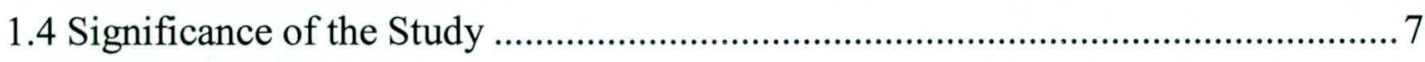

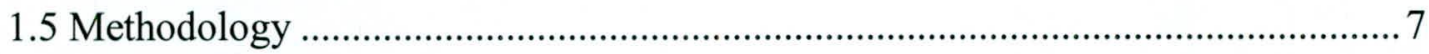

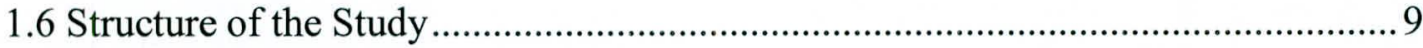

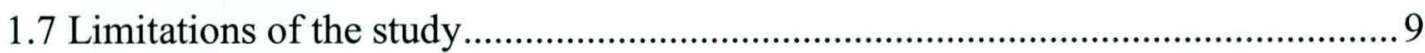

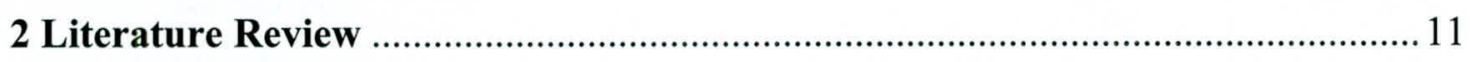

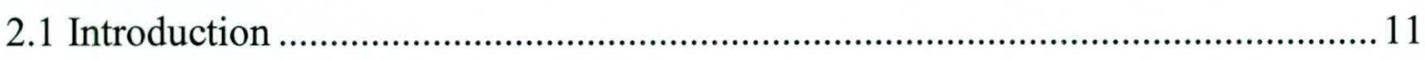

2.2 Emergence of concept of Balanced Scorecard ................................................... 11

2.3 Other performance measurement frameworks ................................................... 14

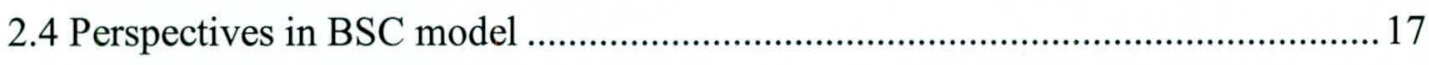

2.5 Balanced scorecard as a technique for performance measurement tool................. 19

2.6 Balanced Scorecard application in Sri Lankan context........................................2 23

2.7 Hotel Sector performance measurement tools.......................................................25

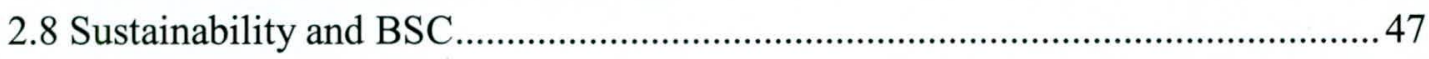

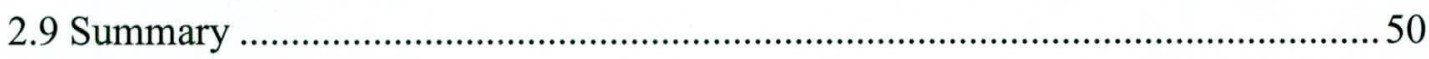

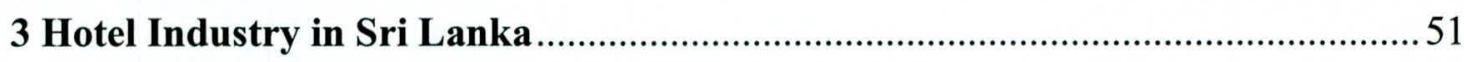

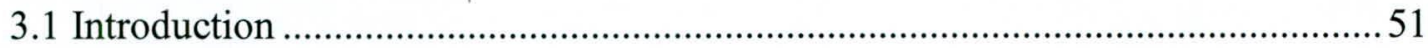

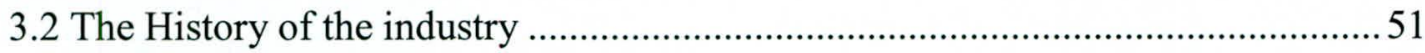

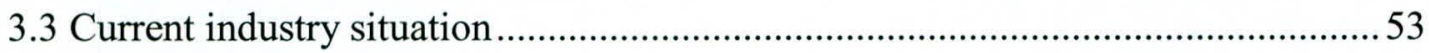

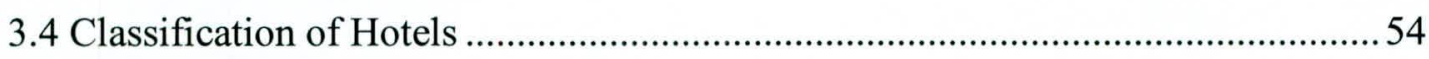

3.5 Brief introduction to case study companies ........................................................5

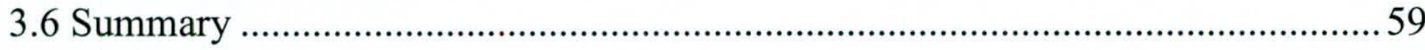

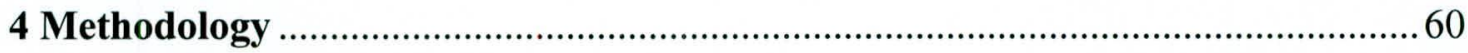

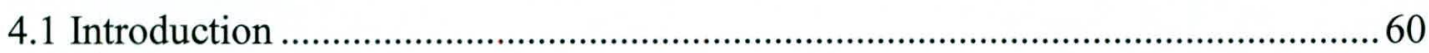

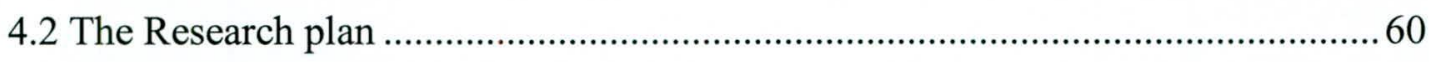

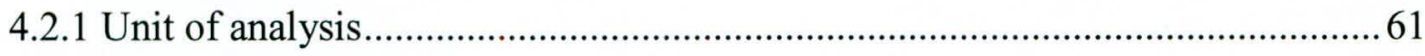

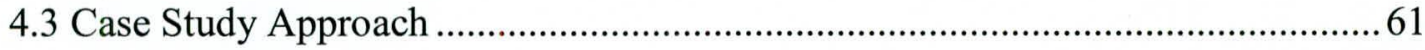

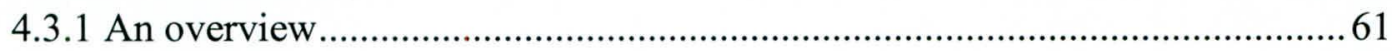


4.3.2 Generalizing from Case study to theory 63

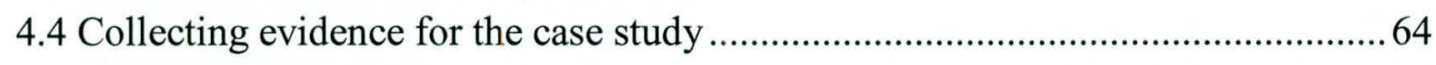

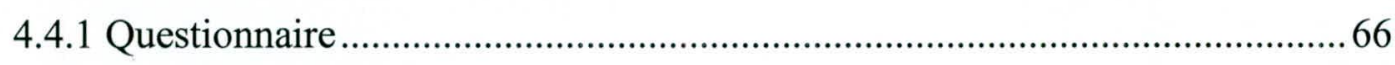

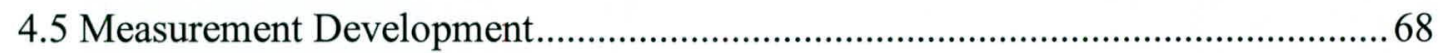

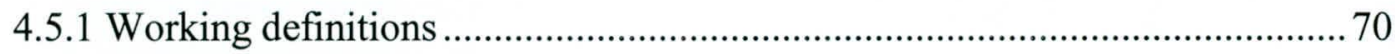

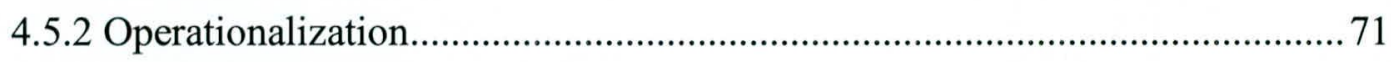

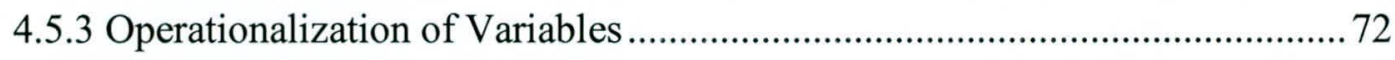

4.5.4 Validity and Reliability of evidence …......................................................... 73

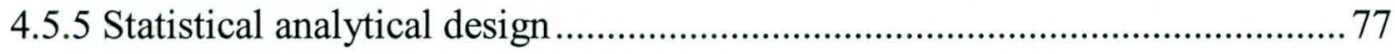

4.5.6 Interviews as a way of obtaining evidence .................................................... 78

4.5.7 Three principals of data collection in a case study ........................................ 80

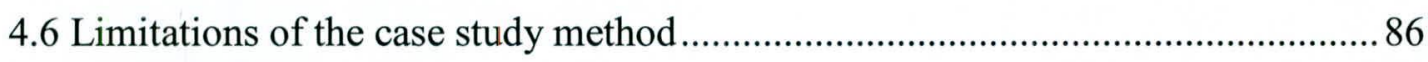

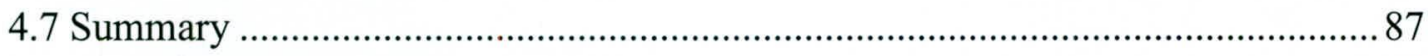

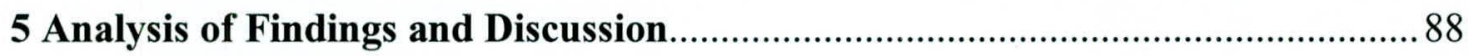

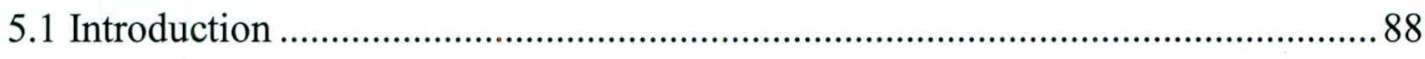

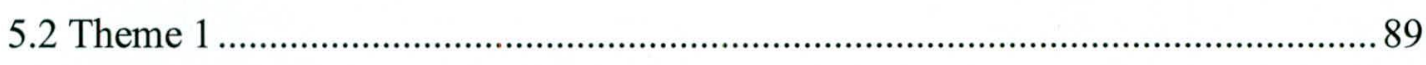

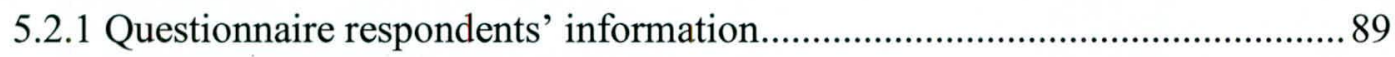

5.2.2 Legal Form of the respondent Companies................................................... 92

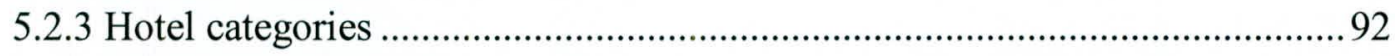

5.2.4 Frequency of financial perspective related performance measures ................ 92

5.2.5 Frequency of Customer perspective related performance measures ...............96 96

5.2.6 Frequency of Internal business perspective related performance measures ... 98

5.2.7 Frequency of innovation and learning perspective related performance measures

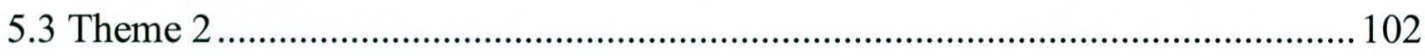

5.3.1 Review of current performance measures using multiple sources of evidence102

5.3.2 Applicability of Balanced Scorecard to the star-class hotels in Sri Lanka... 125

5.3.3 Balanced Scorecard implementation process with emphasis on emerging issues in star-class hotels in Sri Lanka to measure performance in an effective way...... 133

5.3.4 Emerging issues while implementing BSC ............................................. 142

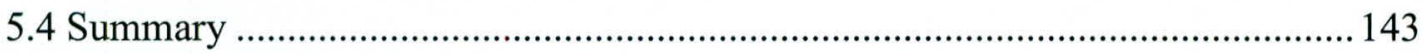

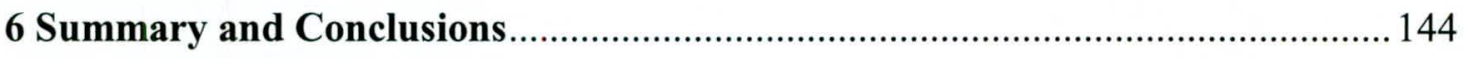

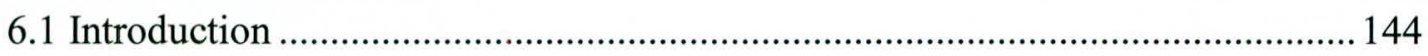




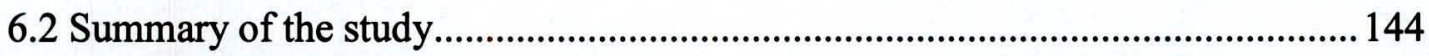

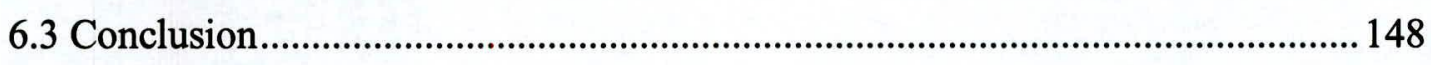

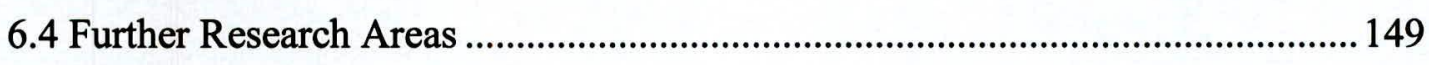

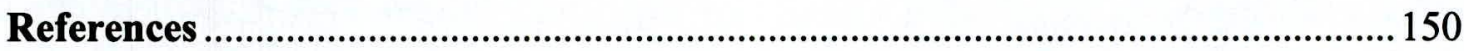




\section{List of Tables}

Table 1.1: Most commonly used performance measures by US hotel companies

Table 4.1: $\quad$ The test - re test results

Table 5.1: Respondents' highest educational qualifications obtained _................91

Table 5.2: Respondents number of total hotel industry experience in years .......91

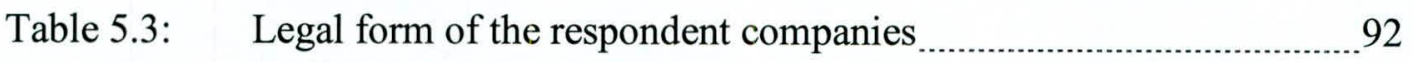

Table 5.4: Frequency of financial perspective related performance measures (count and percentage)

Table 5.5: Frequency of customer perspective related performance measures (count and percentage)

Table 5.6: Frequency of internal business perspective related performance measures (count and percentage) 98

Table 5.7: Frequency of innovation and learning perspective related performance measures (count and percentage) 100

Table 5.8: Food income allocation per one guest $\quad$................................................... 107

Table 5.9: Understanding the vision of the organization

Table 5.10: Understanding the availability of sound information systems within star-class hotels in Sri Lanka 130 


\section{List of Figures}

Figure 2.1: $\quad$ BSC model introduced by Kaplan and Norton ..................................... 13

Figure 2.2: Performance Measurement Frameworks

Figure 2.3: $\quad$ Significant Performance Measurement Studies in Hospitality Industry

Figure 2.4: Financial perspective CSFs and measures _..................................... 31

Figure 2.5: Customer perspective CSFs and measures .......................................... 31

Figure 2.6: Internal business perspective CSFs and measures _.......................... 32

Figure 2.7: Innovation and learning perspective CSFs and measures

Figure 2.8: Areas of research and critical success factors identified _.................... 33

Figure 2.9: Hotel sector balanced scorecard

Figure 2.10: Kala's proposed BSC model for hospitality industry based on

Kaplan \& Norton 38

Figure 2.11: The five key dimensions of SERVQUAL model and the variables ... 47

Figure 4.1: Relevant situations for different research strategies _.........................62

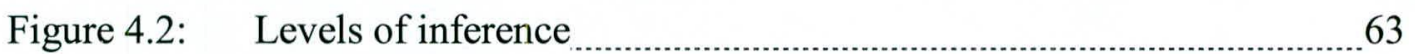

Figure 4.3: Strengths and Weaknesses of Six sources of Evidence _....................64

Figure 4.4: Variables and its dimensions used for the questionnaire ..................... 73

Figure 4.5: Convergence and non-convergence of multiple sources of evidence 81

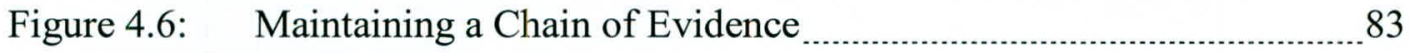

Figure 4.7: Basic Types of Designs for Case Studies

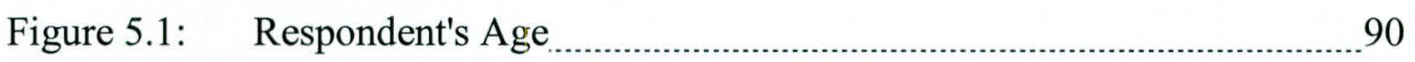

Figure 5.2: Existing financial perspective related measures of Star-class hotels in Sri Lanka

Figure 5.3: Existing customer perspective related measures of Star-class hotels in Sri Lanka.

Figure 5.4: Existing internal business perspective related measures of Star-class hotels in Sri Lanka

Figure 5.5: Existing innovation and learning perspective related measures of Starclass hotels in Sri Lanka

Figure 5.6: Emerging issues while implementing BSC 142 


\section{Abbreviations}

$\begin{array}{ll}\text { BSC } & \text { - Balanced Scorecard } \\ \text { CBSL } & \text { - Central Bank of Sri Lanka } \\ \text { CSF } & \text { - Critical success factors } \\ \text { DMC } & \text { - Distance management companies } \\ \text { FIT } & \text { - Free individual traveler } \\ \text { GDP } & \text { - Gross domestic production } \\ \text { IT } & \text { - Information Technology } \\ \text { SBSC } & \text { - Sustainable balanced Scorecard } \\ \text { SLTDA } & \text { - Sri Lanka Tourism Development Authority }\end{array}$




\section{Acknowledgement}

The completion of this research study as a part of the MBA programme is a valuable experience to me, which provided me with great satisfaction. I consider it is a privileged to offer my sincere thanks to all those who helped me in numerous ways in bringing out this research.

I wish to express my special thanks to our coordinator of MBA programme, Dr. Janak Kumarasinghe who gave me valuable guidelines and coordination to conduct this research study.

I would like to express my deep and sincere gratitude to my supervisor, Dr. Dileepa N. Samudrage, Senior Lecturer, University of Sri Jayewardenepura. Her wide knowledge and logical way of thinking has been valuable to me in providing a good basis for the research.

I am also grateful to Dr. A R Ajward, Senior Lecturer of Department of Accounting, University of Sri Jayewardenepura, Sri Lanka. His support and encouragement enormously motivated me to complete the study effectively.

I wish to also acknowledge Mr. Herman Perera, Human Resource Consultant, Sierra Construction (Private) Limited. His proof reading and constructive comments provided a valuable addition to the research.

I express my gratitude to sample case study hotel managers, whose gave fullest corporation me to collect necessary data for the research study and to the star-class hotel managerial level staff whose supported me by filling the questionnaires.

I owe my loving thanks to my father, mother and my wife who gave support and encouragement for the research. Without their sacrifices, patience, encouragement and moral support, completion of this task would not have been possible.

H.M.S.R. Dayabandara 


\title{
Implementation of the Balanced Scorecard as an effective performance measurement system in star-class hotels in Sri Lanka
}

\author{
H.M.S.R. Dayabandara
}

\begin{abstract}
The aim of the study is to examine how balanced scorecard is developed and implemented as an effective organizational performance measurement system in star-class hotels in Sri Lanka. Hotel sector is one of rapidly growing industry in Sri Lanka playing a significant role in national economy. The identification of hotel industry performance is essential to understand the direction of the industry. Therefore hotel industry performance was identified with one of well accepted performance measurement tool; BSC which considers important four perspectives of performance measures.
\end{abstract}

The mixed method was used for the study using research tool of multiple case study method. Questionnaire, interviews and documentary reviews were used to gather data for the study.

The study identified that many hotels concern more about financial and customer perspectives when measuring hotel performances and low attention was given to internal business and innovation and learning perspectives. Interviews raised the ability of starclass hotels to apply BSC as a tool of organizational performance measurement while addressing some of the matters related to implementation. Based on interviews and related literature, BSC implementation process was developed specially applying to star-class hotels in Sri Lanka. The study suggests properly developed balanced scorecard based 
performance measurement system will contribute to generate more accurate information and drive the business to the success.

Key Words: Balanced Scorecard, Performance Measurement, Star-class Hotels in Sri Lanka 


\section{Chapter One \\ Introduction}

\subsection{Background of study}

Hotel sector is one of the rapidly growing industries in Sri Lanka playing a significant role in national economy. It contributes rupees 69,105 million to the gross domestic production (GDP) and which is $0.796 \%$ to the total GDP in the year 2013 (CBSL Annual report, 2013). During the recent decades especially during the pre and post conflict period, the tourism industry has become an effective source for monetary gains and economic growth (Karunarathne and Jayawardena, 2010).

Based on year 2013 annual report of Central bank of Sri Lanka, hotels and restaurants industry contributes $1.4 \%$ to total service sector (Annexure 1). Although it has a low contribution to the gross domestic production, it shows a massive growth during the last five years. For instance from 2010 to 2013 the hotel sector has recorded a growth of $33 \%, 33 \%, 31 \%$ and $19 \%$ respectively. Therefore the hotel sector is very important growing element in the national economy. Further it was evident that the industry was identified by Central Bank of Sri Lanka as one of Hub activities to achieve sustainable growth in Sri Lanka.

There are 2,075 registered hotels and restaurants in Sri Lanka by 2013 with a total room capacity of 16,223 . During the year 2013, the industry has reported annual occupancy ratio of $71.7 \%$. (CBSL annual report, 2013). Further the industry contributed to direct 
employment of 112,550 workers and indirectly 157,600 employment opportunities during the year 2013.

As a result of post -conflict growth momentum, the country attracted more than 1.2 million guest arrivals in the year 2013. Evan though the estimated arrivals was 950,000 in the year 2012, it recorded $1,005,605$ with the growth of $18 \%$ compared to previous year. When identifying the tourist arrivals in terms of the region, Western Europe contributes $37 \%$ while South Asian remains at second with the contribution of $25 \%$ in 2012. With regard to the arrivals from individual countries, India remaining at the leading source of arrivals. Other major tourist arrivals come from UK, Germany, France and Australia respectively.

Earnings from the tourism increased substantially due to increase in arrivals and increase in average spending per guest in 2012. Earning from tourism industry for the year 2012 was US $\$ 1,039$ million compared to US $\$ 830$ million reported in previous year. Further average spending by guest per night increased to US $\$ 103$ in 2012, from US \$ 97 in 2011.

Sri Lanka Tourism Development Authority (SLTDA) took strategic initiatives to attract 2.5 million guest arrivals with the target revenue of US $\$ 2.75$ billion in 2016 . Further industry wide investments were made to enhance capacity by introducing new tourist zones in Kalpitiya, Kuchchaweli and Yala under different themes. International hotel chains such as Shangri-La Asia, Hyatt, Movenpick and Sheraton also expected to start 